\title{
Coulomb Stress Change Sensitivity due to Variability in Mainshock Source Models and Receiving Fault Parameters: A Case Study of the 2010-2011 Christchurch, New Zealand, Earthquakes
}

\author{
Zhongwen Zhan, ${ }^{1,2}$ Bikai Jin, ${ }^{3}$ Shengji Wei, ${ }^{1}$ and Robert W. Graves ${ }^{4}$
}

\section{INTRODUCTION}

Strong aftershocks following major earthquakes present significant challenges for infrastructure recovery as well as for emergency rescue efforts. A tragic instance of this is the 22 February $2011 M_{w} 6.3$ Christchurch aftershock in New Zealand, which caused more than 100 deaths while the $2010 M_{w} 7.1$ Canterbury mainshock did not cause a single fatality (Figure 1). Therefore, substantial efforts have been directed toward understanding the generation mechanisms of aftershocks as well as mitigating hazards due to aftershocks. Among these efforts are the prediction of strong aftershocks, earthquake early warning, and aftershock probability assessment. Zhang et al. (1999) reported a successful case of strong aftershock prediction with precursory data such as changes in seismicity pattern, variation of $b$-value, and geomagnetic anomalies. However, official reports of such successful predictions in geophysical journals are extremely rare, implying that deterministic prediction of potentially damaging aftershocks is not necessarily more scientifically feasible than prediction of mainshocks.

A potentially more effective approach for aftershock hazard mitigation is described by Bakun et al. (1994) for the case of the Loma Prieta earthquake. This approach relies on the rapid detection of an aftershock using a dense observation network in the rupture area of the mainshock and subsequent broadcast of an alert to more distant sites. Recent progress in rapid determination of epicenter and magnitude involving a

1. Seismological Laboratory, California Institute of Technology, Pasadena, California 91125 U.S.A.

2. Mengcheng National Geophysical Observatory, School of Earth and Space Sciences, University of Science and Technology of China, Hefei 230026 China

3. Key Laboratory of Dynamic Geodesy, Institute of Geodesy and Geophysics, Chinese Academy of Sciences, Wuhan 430077 China

4. U.S. Geological Survey, 525 South Wilson Avenue, Pasadena, California, 91106 U.S.A. small number of stations and short time window of $P$ waveforms (Allen and Kanamori 2003; Wan et al. 2009; Wang et al. 2009) make the approach of earthquake early warning more effective for regions not very close to the rupture area of the mainshock. Such an approach might have been useful for aftershocks of the 2008 Wenchuan earthquake, where megacities such as Chengdu are about $90 \mathrm{~km}$ away and 20 seconds were available for rapid mitigation response. But in the case of the 2011 Christchurch earthquake, the populated region is only about $10 \mathrm{~km}$ from the epicenter, thus leaving little time for early warning.

For a situation such as Christchurch, aftershock probability assessment may provide a viable approach to address the hazard level. Several aftershock-triggering mechanisms, i.e., the static Coulomb stress theory (King et al. 1994; Stein 1999), the dynamic triggering theory (Felzer and Brodsky 2006), and viscoelastic relaxation theory (Freed et al. 2001), can be applied to assess aftershock probabilities. In this paper we will concentrate on how applicable the static Coulomb stress triggering mechanism is to the 2011 Christchurch aftershock and examine the sensitivity of the stress changes to mainshock slip distribution and aftershock fault orientation. The Coulomb stress theory has been broadly applied in aftershock studies (e.g., King et al. 1994; Parsons et al. 1999; Toda et al. 1998; Ma et al. 2005), earthquake sequencing (Stein et al. 1997; Xiong et al. 2010; Nalbant et al. 1998) and the triggering of large to moderate earthquakes (Parsons et al. 2000). Previous studies (e.g., Harris 1998, 2000; Freed 2004; King et al. 1994; Stein 1999) proposed a Coulomb stress change of $0.01 \mathrm{MPa}$ to be the threshold for potential earthquake triggering.

The Coulomb stress triggering theory involves computing the change in normal traction and shear traction on a fault (receiving fault) caused by changes of the stress field due to the mainshock. Therefore, accurate information on the receiving fault geometry (strike, dip, rake, and focal depth) and source model of the mainshock are necessary for effective assessment 




A Figure 1. Seismicity in the first three days after the 2010 Canterbury mainshock (color-scaled dots) and the 2011 Christchurch aftershock (dots in gray scale). The red lines are the free surface rupture trace from field observation. The big red star indicates the epicenter of the main event and the smaller red star is the location of the $M_{w} 6.3$ aftershock. The GCMT solution of mainshock and the cut-and-paste (CAP) mechanism of the aftershock are shown as beach balls. The black rectangles are the free surface projection of the two-segment model, which are used in the teleseismic finite fault inversion. The yellow rectangles are for the four-segment model used in the stochastic slip model.

of aftershock probability. Due to inadequate coverage of seismic and geodetic observation systems and inaccurate 3D Earth structure models, there are always errors in the source models of the mainshock. Moreover, fault geometries of future aftershocks are not precisely known, and aftershocks occurring on blind faults are particularly difficult to study due to lack of geological information about the faults. For example, the 1994 Northridge earthquake occurred on a blind (buried) fault; the study of its potential triggering by the 1971 San Fernando earthquake was only made possible after its rupture plane and hypocenter depth were resolved (Stein et al. 1994). The 2011 Christchurch earthquake was another case of such a blind earthquake, which has not yet been associated with any known geological faults. Thus, this event is a valuable case study of how effective the Coulomb stress mechanism is in triggering aftershocks, and its variability due to the uncertainties in receiving fault parameters and mainshock source models.

In this paper we examine the sensitivity of computed static Coulomb stress change levels to source parameterization by considering various combinations of mainshock rupture models and aftershock fault orientations for the 2010 Canterbury and 2011 Christchurch earthquakes. General constraints on the mainshock source models and aftershock fault geometry are provided by teleseismic and geodetic data. We also investigate the sensitivity of the results to aftershock focal depth and apparent coefficient of friction. We conclude with a discussion of how these results can be used in combination with focal mechanism studies to help constrain aftershock rupture assessment using Coulomb stress change calculations.

\section{GENERAL INFORMATION ON THE $\boldsymbol{M}_{w} 7.1$ CANTERBURY EARTHQUAKE AND THE $M_{w} 6.3$ CHRISTCHURCH EARTHOUAKE}

The Australian and Pacific plates converge obliquely at about $40 \mathrm{~mm} \mathrm{yr}^{-1}$ at New Zealand. Partly due to along-strike variations in the orientations of both the plate boundary and the direction of relative motion between the plates, the defor- 
mation takes on a larger strike-slip component southward (Wallace and Beavan 2006). Accordingly, the style of deformation changes southward, from subduction of the Pacific plate and back arc rifting in the North Island to nearly pure strike-slip in the Marlborough region to oblique convergence in the central South Island (causing formation of the central Southern Alps) and back to subduction of the Australian plate at the Fiordland subduction zone in the southwestern South Island (Wallace and Beavan 2006). The earthquake sequence we study in this paper occurred in the central South Island. The 2010 Canterbury earthquake occurred at 4:35 A.M. local time on 4 September (16:35 UTC, 3 September), on a previously unrecognized fault system, the Greendale fault (Figure 1) (Quigley et al. 2010). This $M_{w} 7.1$ earthquake caused widespread damage throughout the area, but no deaths and only two injuries were reported despite the epicenter's location about $40 \mathrm{~km}$ west of Christchurch (population 386,000), New Zealand's second-most populated city (Quigley et al. 2010). The 2011 Christchurch earthquake occurred at 12:51 P.M. on 22 February 2011 local time (21 February UTC), causing widespread damage and more than 100 fatalities. The earthquake was centered $2 \mathrm{~km}$ west of the town of Lyttelton and $10 \mathrm{~km}$ southeast of the center of Christchurch.

\section{SOURCE MODELS OF THE 2010 CANTERBURY EARTHQUAKE}

The $2010 M_{w} 7.1$ Canterbury earthquake ruptured the previously unrecognized Greendale fault in an east-west direction for $\sim 30 \mathrm{~km}$ (Figure 1). The average displacement of this predominantly right-lateral strike-slip event is $\sim 2.5 \mathrm{~m}$, with maxima of $\sim 5 \mathrm{~m}$ (Van Dissen et al. 2011). The first finite fault slip model of the main event was published by the U.S. Geological Survey (http://earthquake.usgs.gov/earthquakes/eqinthenews/2010/ us2010atbj/finite_fault.php), in which teleseismic body waves were used for the inversion assuming a single fault plane. The GPS and InSAR data were collected later on and a static slip model was derived by Beavan et al. (2010). Compared with the single fault plane model, this static slip model is composed of six segments, consisting of the strike-slip Greendale fault and several thrust faults.

To address the variability of static triggering due to mainshock rupture models, we analyze: 1) a single fault plane model with uniform slip; 2) a two-segment slip model from teleseismic body wave inversion; and 3) two stochastic slip models. Despite its simplicity, a uniform slip model can provide a straightforward physical picture and can explain the main features of some earthquakes (e.g., Talebian et al. 2006). Also, it is a good reference for comparison with results generated from other slip models. First we use the Global Centroid Moment Tensor (GCMT) solution to define the fault geometry and the rake angle for the uniform slip model. We choose the fault plane with strike of $87^{\circ}$ and dip of $85^{\circ}$, since the strike is consistent with the rupture trace on the free surface (Figure 1). Slip with an amplitude of $3 \mathrm{~m}$ and rake of $172^{\circ}$ is uniformly distributed on the rectangle fault plane, which is $42 \mathrm{~km}$ along strike and $12 \mathrm{~km}$ along dip. However, because of the complexity of this earthquake, it is hard to fit the waveforms with this simple slip model (Figure 2). Poor waveform fits are also shown in the USGS results (http://earthquake.usgs.gov/earthquakes/ eqinthenews/2010/us2010atbj/finite_fault.php).

To investigate the potential for additional complexity in the rupture geometry, we derive a two-segment finite fault slip model by inverting teleseismic body waves. We collected 27 teleseismic $P$ waves and $15 S H$ waves from the earthquake. Stations are selected based on data quality and azimuthal coverage (Figure 3). To derive the finite fault model, we use the approach developed by Ji et al. (2002a, 2002b), which allows fitting of seismic waveforms in the wavelet domain. Nowadays, similar procedures are run routinely by several agencies, such as the USGS (http://earthquake.usgs.gov/earthquakes/eqinthenews/) and the Caltech Tectonics Observatory (http://www. tectonics.caltech.edu/slip_history/). By examining the seismicity in the first three days after the 2010 Canterbury earthquake, we can observe a linear distribution of aftershocks in the north-south direction crossing roughly perpendicular to the mapped surface rupture trace. The epicenter of the mainshock is also located within this linear band of seismicity (Figure 1). This suggests the possibility that more than one fault was involved in the rupture. Thus, we added one more fault plane with strike along this seismicity trend (strike of $345^{\circ}$ and dip of $75^{\circ}$ ) into the finite fault inversion. The epicenter is specified to be on this fault plane with depth of $\sim 7 \mathrm{~km}$; thus we assume the earthquake initiated on the north-south trending fault and propagated to or triggered the rupture on the other fault later on. The waveform fitting of the two-fault plane model is much better than that of the single fault plane model, especially for the beginning portion of some $P$-wave records (Figure 3 ). For example, station PSI's $P$ waveform, which is not fitted in the single fault plane inversion, is now fitted well. The slip distribution on the first segment shows mainly thrust motion, which is required to fit positive first motions of some $P$ waves. The largest slip patch is on the second fault plane and is dominated by strike-slip motion. Some thrust motion is also shown in the western part of the second fault plane. The rupture length and the location of thrust motion in our model are consistent with field observations and static inversion results (Beavan et al. 2010; Van Dissen et al. 2011).

The stochastic slip model is another approach for characterizing the slip distribution of an earthquake, and it has been widely applied in ground motion simulations (Mai and Beroza 2002; Liu et al. 2006; Graves and Pitarka 2010). Lavallée and Archuleta (2003) found that the slip distribution of the 1979 Imperial Valley earthquake could be well modeled with a stochastic model assuming power law of $k^{-n}$, where $k$ is the wavenumber. A stochastic approach has to be taken in the following two cases. The first case is when studying historical earthquakes, which lack seismic waveform or geodetic data for finite fault inversion, as with the 1811/1812 New Madrid earthquakes. The other case is when characterizing the rupture for scenario earthquakes. For the Canterbury earthquake, we follow the procedure by Graves and Pitarka (2010) to gener- 


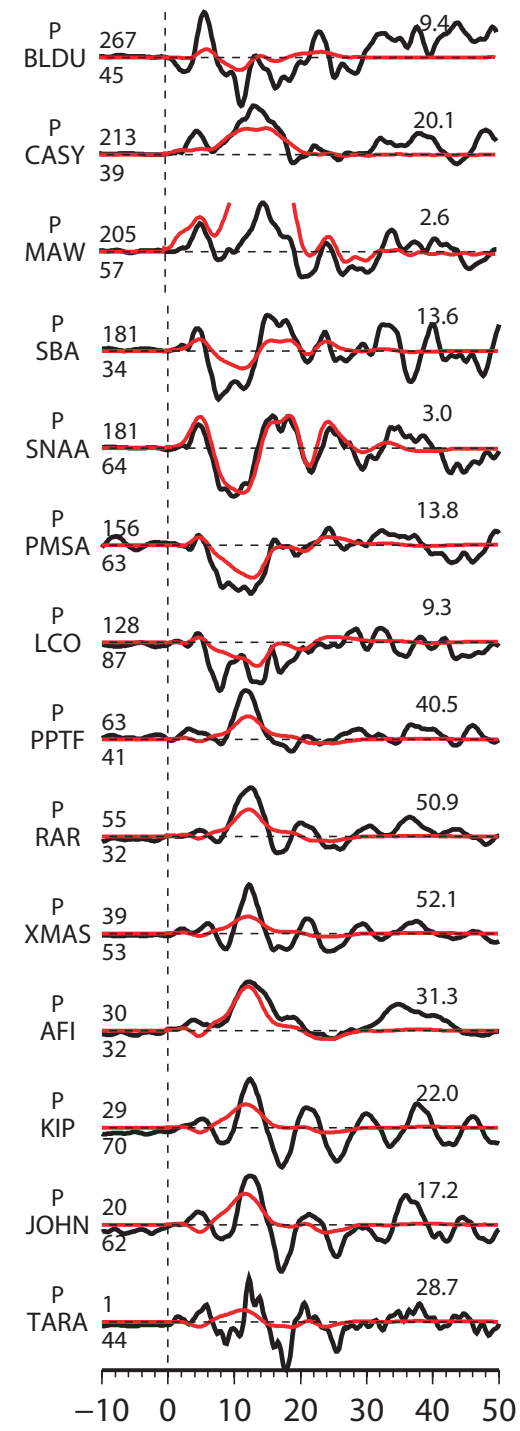

$\mathrm{S}$
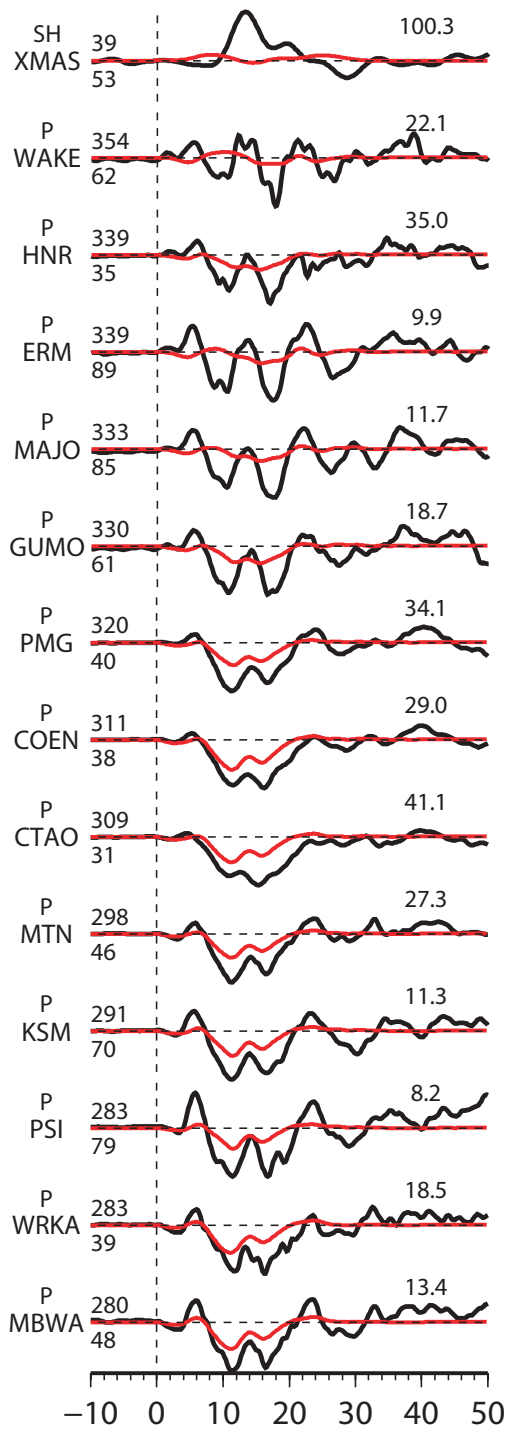

$\mathrm{S}$
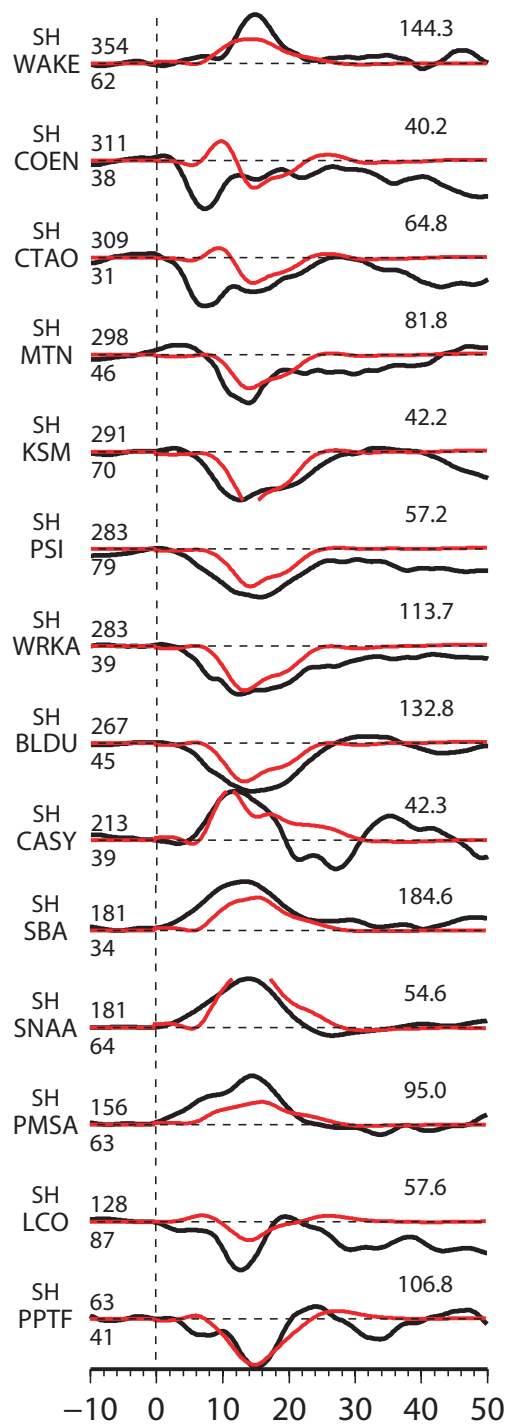

$\mathrm{S}$

$\Delta$ Figure 2. Waveform fits for the single fault plane inversion. Black lines are data in displacement and red are synthetic. Station names are displayed to the left of the traces along with the azimuths (above) and epicentral distances in degrees (below). Peak amplitude (in microns) for the data is indicated above the end of each trace.

ate stochastic rupture models. We generated two models, one model with only a single fault segment (Figure 4) and the other with four fault segments, which were derived by simplifying the model of Beavan et al. (2010) (Figure 5).

\section{FAULT PARAMETERS OF THE 2011 CHRISTCHURCH EARTHOUAKE}

To study the effect of receiving fault geometry on Coulomb stress change, we need to determine the focal mechanism and focal depth of the 2011 Christchurch earthquake. There are many different approaches for studying earthquake source parameters using regional or teleseismic waveforms. Two kinds of regional waveform data are generally used: surface waves and body waves. Since surface waves are generally much stronger than body waves, full waveform inversions are mainly controlled by surface waves. Dreger and Helmberger (1993) used the long-period body waves recorded by a regional sparse network to invert for focal mechanism. Later, Zhao and Helmberger (1994) and Zhu and Helmberger (1996) developed the "cut and paste" (CAP) technique, which breaks broadband waveforms into $P n l$ and surface wave segments and inverts them independently, allowing for different bandpass filtering, time shifts, and weights. The CAP technique has been successfully applied to determine the depth and focal mechanism in many regions (e.g., Tan et al. 2006). However, regional data are not always accessible immediately after earthquakes, so inversion techniques using teleseismic waveforms become important and are routinely used to estimate source parameters for earthquakes of $\mathbf{M} 6$ and above (e.g., the Global CMT solution, the USGS body wave moment tensor solution, and the USGS Wphase solution). Most of these automatic approaches involve 

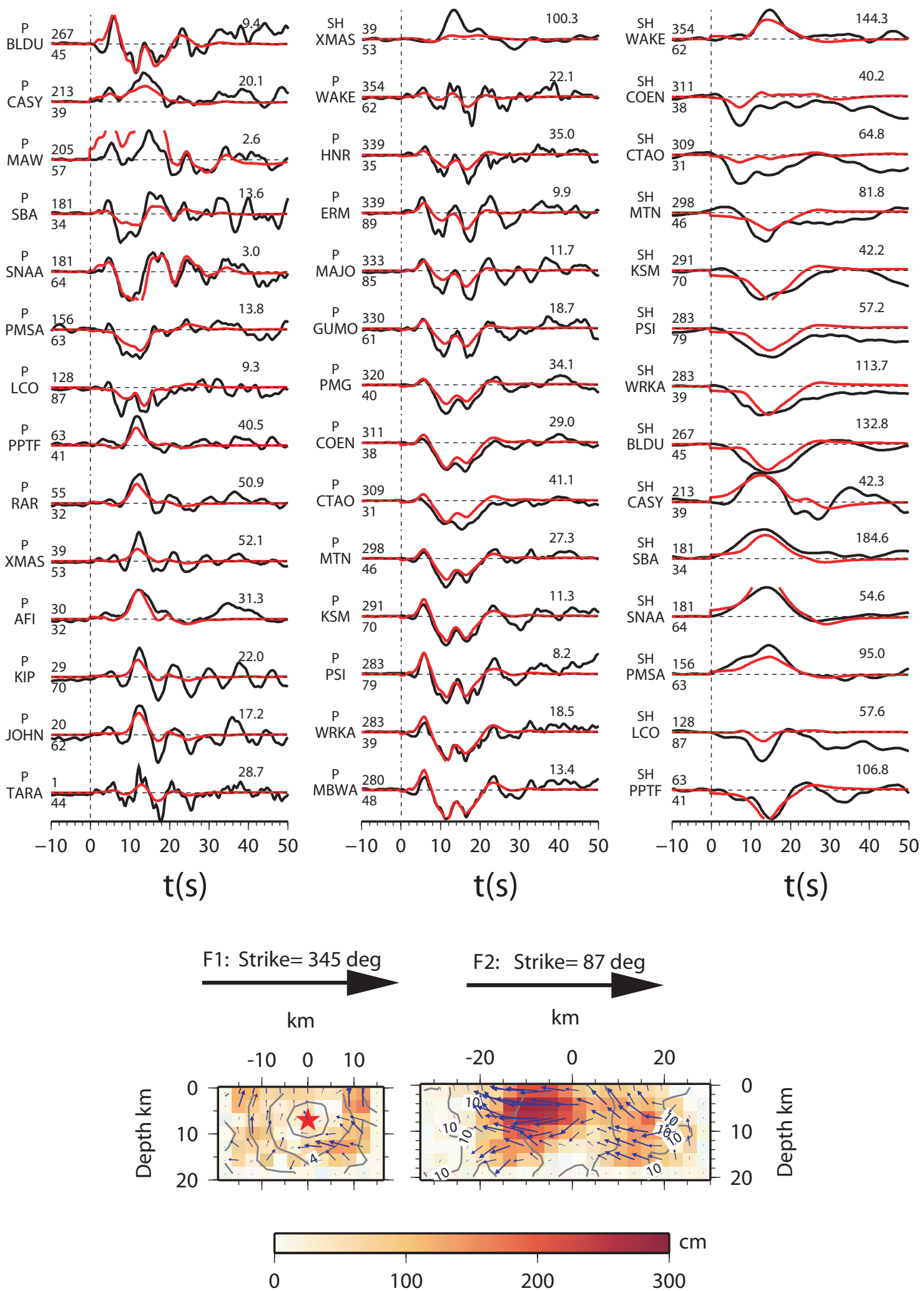

A Figure 3. Results of the two-segment finite fault inversion. The upper panel shows the displacement waveform fits in black for the data and red for the synthetic. Station names are displayed to the left of the traces along with the azimuths and epicentral distances in degrees. Peak amplitude (in microns) for data is indicated above the end of each trace. The lower panel shows the cumulative slip distribution (slip vectors with amplitude of slip also represented by color shading) and time contours of the rupture propagation as determined by the inversion. The rupture times are given relative to the origin time, and the red star indicates the epicenter. The strike of each segment is shown on the top. 


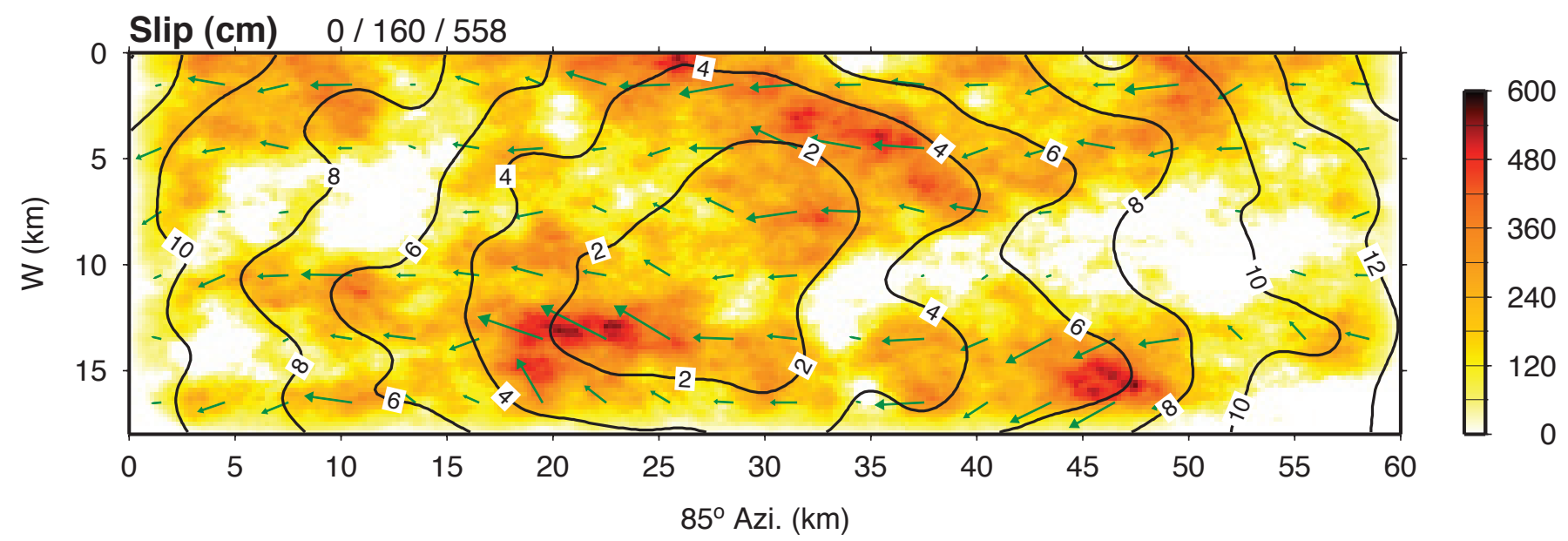

A Figure 4. A stochastic single-segment slip model of the 2010 Canterbury earthquake. The background color shows the distribution of cumulative slip in centimeters and the green arrows show the slip vectors. Time contours of the rupture propagation are shown as black contours. The rupture times (numbers on the contour lines) are given relative to the origin time. The strike of the fault plane is shown at the bottom.

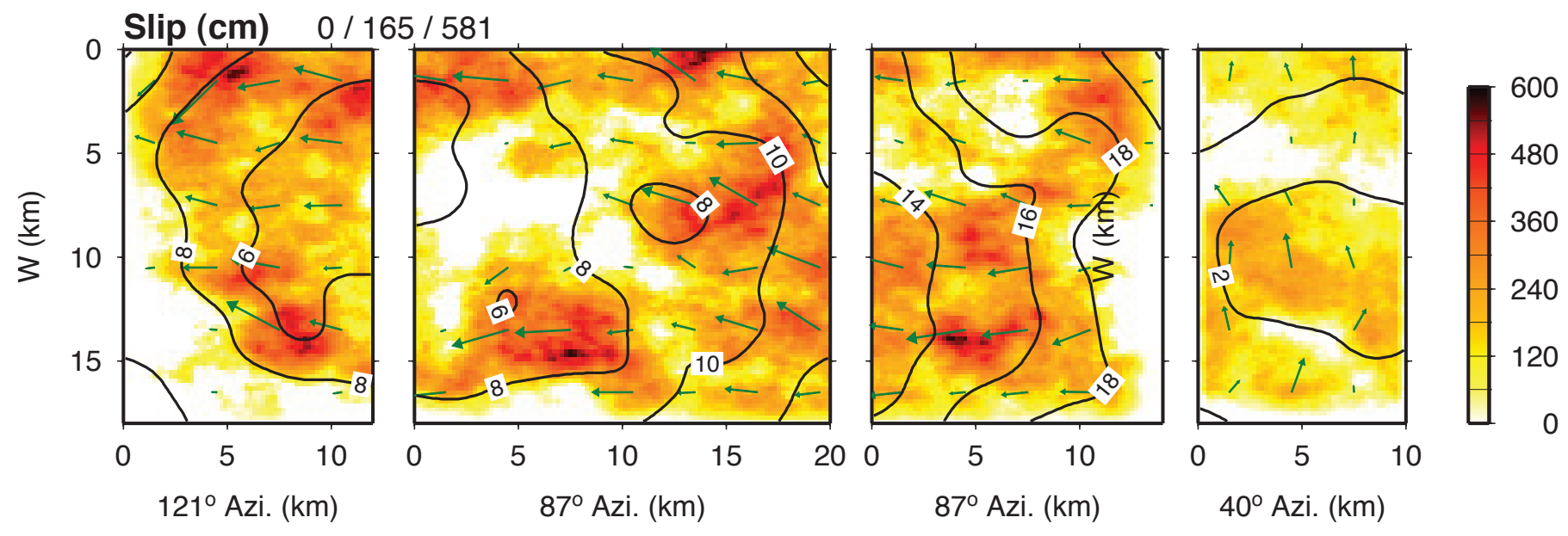

A Figure 5. Stochastic multiple-segment slip model of the 2010 Canterbury earthquake. The background color shows the distribution of cumulative slip in centimeters and the green arrows show the slip vectors. Time contours of the rupture propagation are shown as black contours. The rupture times (numbers on the contour lines) are given relative to the origin time. The strikes of the fault segments are shown at the bottom of each panel.

long-period waves so the solutions have poor resolution of earthquake depth. Also when the earthquake is shallow, strong trade-off among depth, focal mechanism, and magnitude can cause large uncertainties in source parameters (Dahlen and Tromp 1998). To overcome these problems, we extend the idea of the regional CAP technique to teleseismic cases (teleCAP). In teleCAP, we cut $10-50 \mathrm{~s}$ period band $P$-wave segments in the vertical components and $S H$-wave segments in the transverse components and fit them independently, allowing different time shifts and weights. We choose the relative weights between $P$ and $S H$ waves so that they contribute almost equally to the final misfit function (e.g., Tan et al. 2006).

Synthetic seismograms are calculated with a $1 \mathrm{D}$ sourceside crustal model obtained from CRUST 2.0 (Bassin et al. 2000). Figure 6 shows the seismic stations used in the inversion. These stations are chosen based on their signal-to- noise ratio $(\mathrm{SNR})$ and azimuthal coverage. We find the best waveform-fitting source parameters by grid-searching earthquake magnitude, focal mechanism (strike, dip, and rake), depth, and source duration. Figure 7 shows the best waveform fitting, the corresponding focal mechanism (strike/dip/ rake $=174^{\circ} / 46^{\circ} / 42^{\circ}$ or $\left.52^{\circ} / 61^{\circ} / 128^{\circ}\right)$ and magnitude $\left(M_{w}\right.$ 6.3). Compared with the Global CMT solution (strike/dip/ rake/magnitude $=167^{\circ} / 57^{\circ} / 32^{\circ}$ or $59^{\circ} / 64^{\circ} / 143^{\circ}, M_{w} 6.1$ ), there is $\sim 10$ degree difference for strike/dip/rake and 0.2 difference in magnitude. These differences will be discussed later. Both $P$ and $S H$ wave amplitudes and waveforms at all azimuths are fit very well. Figure 8 shows the waveform misfit as functions of centroid depth and source duration; the best fitting depth is $5 \mathrm{~km}$, which is the same as reported by New Zealand local seismologists using local stations. The best fitting source duration is $6 \mathrm{~s}$, the same as in the Global CMT solu- 


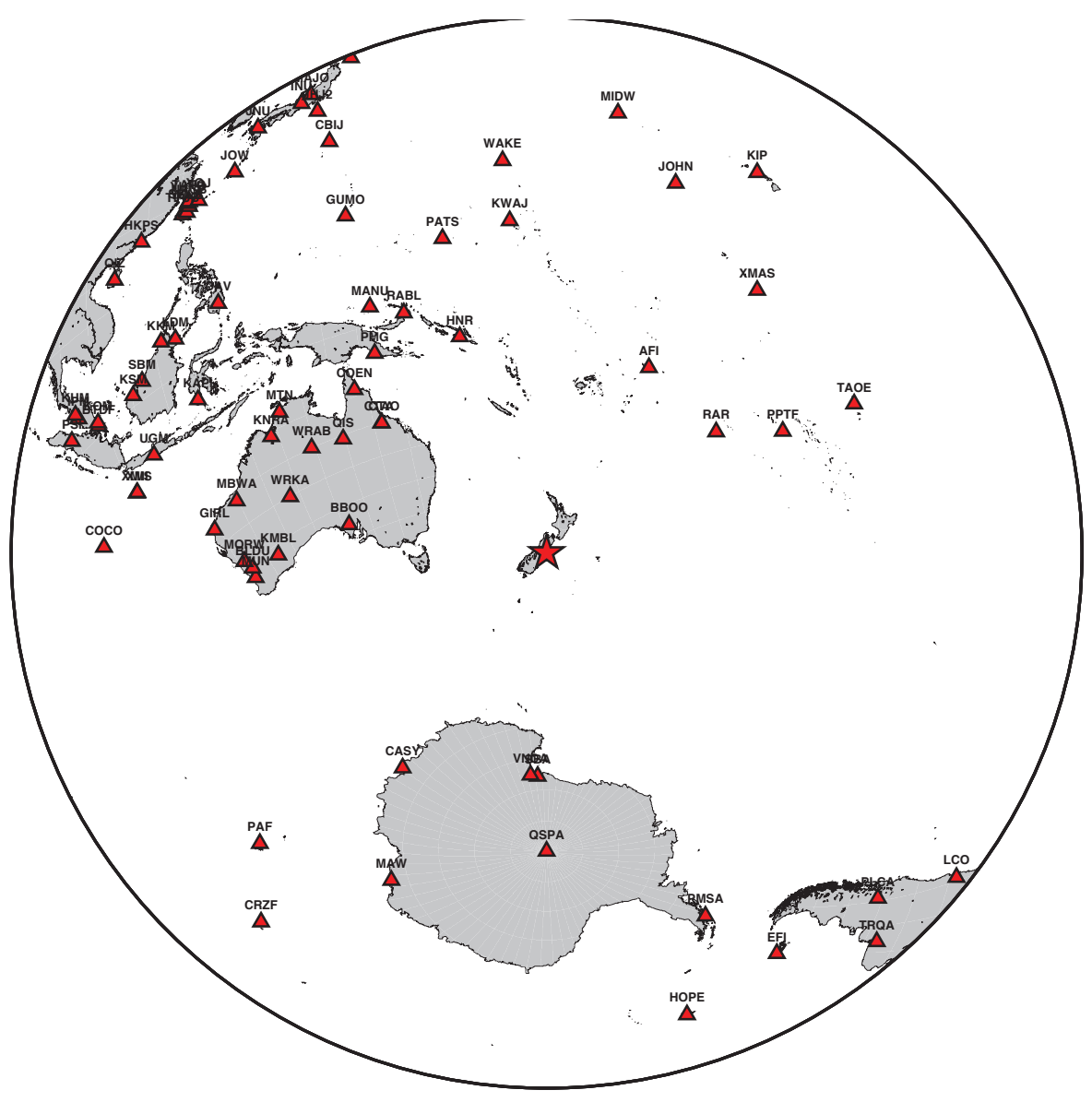

A Figure 6. Seismic stations used in the inversion of fault parameters of the 2011 Christchurch earthquake. These stations are chosen based on their signal-to-noise ratio (SNR) and azimuthal coverage.

tion. For each candidate depth and source duration, we also plot its best fitting focal mechanisms and magnitudes in Figure 8 , to show the trade-off between magnitude and other source parameters. Obviously, the earthquake magnitude decreases as depth increases, as expected from the free surface effects as discussed by Dahlen and Tromp (1998). If depth $=12 \mathrm{~km}$ (as determined in the Global CMT), the magnitude will be about $M_{w} 6.15$, which is close to the $M_{w} 6.1$ in the GCMT catalog. Due to the trade-off between depth and focal mechanism for shallow events, the GCMT's focal mechanism may also be somewhat biased. We conclude that teleCAP provides higherresolution source parameters for the 2011 Christchurch earthquake. However, it should be noted that teleCAP assumes a double-couple point source, as do most other approaches, so it cannot distinguish between the fault plane and auxiliary fault plane. The first three days' aftershock distribution of the 2011 Christchurch earthquake shows a clear linear trend from EEN to WWS (Figure 1), which prefers the fault plane $52^{\circ} / 61^{\circ} / 128^{\circ}$. In the following discussion we will use only this fault plane. Epicenter location is another important source parameter that will greatly affect the computation of Coulomb stress change. In this paper, we use the epicenter location from New Zealand GeoNet, which is based on data from a dense local seismic network and is presumably accurate.

\section{COMPUTATION OF COULOMB STRESS FOR VARIOUS MAINSHOCK SOURCE MODELS AND RECEIVING FAULT GEOMETRIES}

Based on the Coulomb failure criterion (Jaeger et al. 2007, 475 ) and the theory of elastic dislocation (Okada 1992), we calculate the coseismic Coulomb failure stress change $\left(\Delta \sigma_{f}\right)$ caused by the mainshock for different mainshock slip models and for different receiving fault geometries. Following King $e t$ al. (1994), $\Delta \sigma_{f}$ is given by $\Delta \sigma_{f}=\Delta \tau_{s}-\mu^{\prime} \Delta \sigma_{n}$, where $\Delta \tau_{s}$ and $\Delta \sigma_{n}$ are the changes in shear and normal stress, respectively, due to the mainshock, and $\mu^{\prime}$ is the apparent coefficient of friction. Here we use the rock mechanics sign convention in which compressive is positive.

In this study, we use the lithosphere model of dislocation sources embedded in an elastic multilayered half space (Wang et al. 2003, 2006) and adopt the program PSGRN/PSCMP (Wang et al. 2006) to compute the static Coulomb stress change produced by the mainshock. Since the influence from the curvature of Earth's free surface is small for this local study (Xiong et al. 2010), the Earth surface is treated as flat in our model. The parameters of our multilayered model in Table 1 are based on Crust 2.0. A moderate value of apparent coefficient of friction $\mu^{\prime}=0.4$ is used in our calculation (King et al. 

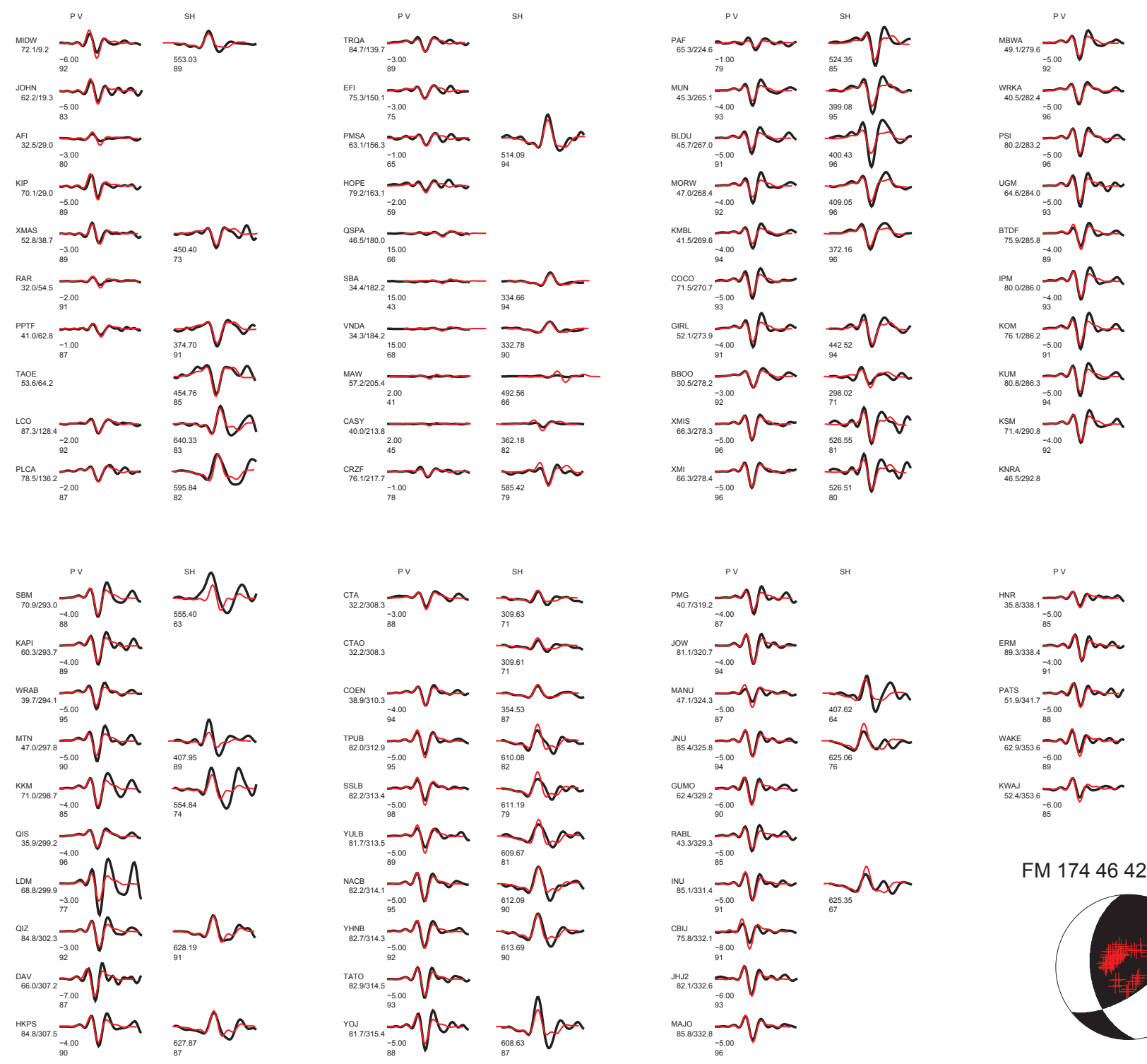

SH
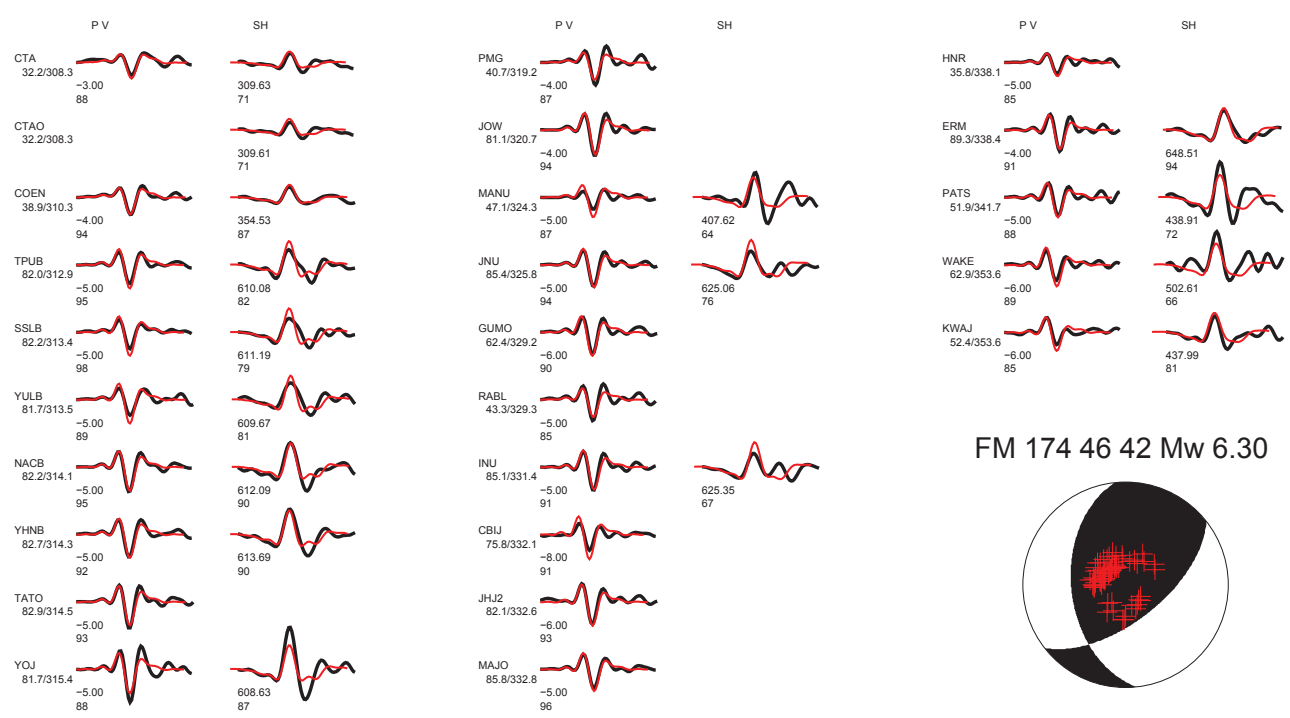

A Figure 7. Best teleseismic waveform fitting and the corresponding focal mechanism (strike/dip $/$ rake $=174^{\circ} / 46^{\circ} / 42^{\circ}$ ) and magnitude $\left(M_{w} 6.3\right)$. Black is the data and red is the synthetic. The red crosses on the focal mechanism beach ball show the locations of stations.

1994), and parameter sensitivity will be discussed. To show the influence of the uncertainty of focal depth, we calculate the $\Delta \sigma_{f}$ caused by the mainshock on several horizontal planes at 2, 5, 10 , and $15 \mathrm{~km}$ depths, respectively, each of which consists of $101 \times 101$ grid points. In the next several subsections, we will show the $\Delta \sigma_{f}$ results for these different cases and discuss their variability. It should be noted that the effect of viscoelastic relaxation is not taken into account here. Because of the short time interval between the two events, its influence is believed to be relatively small, compared with the uncertainties of other parameters above. More accurate results can be achieved by taking this effect into account in the future.

\section{Coulomb Stress Change Caused by Different Mainshock Slip Models}

The selection of an appropriate mainshock slip model is important for the $\Delta \sigma_{f}$ distribution. Figure 9 displays the $\Delta \sigma_{f}$ distribu- tion for the four slip models discussed previously. In all cases, the slip models have a strong influence on the $\Delta \sigma_{f}$ distribution along the Greendale fault in the near field. For example, the Greendale fault lies completely within a stress shadow in Figure $9 \mathrm{~A}$, but there are some parts significantly loaded (>1MPa) using the other three models in Figure 9B-D. However, these different slip models cause no significant difference in the far field. At the eastern and western ends of the Greendale fault, the stress changes more than $0.01 \mathrm{MPa}$ caused by each model, and the $\Delta \sigma_{f}$ distributions, are very similar. In summary, it can be inferred that a uniform slip model can explain the main features of the $\Delta \sigma_{f}$ distribution in the far field; the more complicated slip models make the $\Delta \sigma_{f}$ distribution heterogeneous in the near-field along the fault. At the hypocenter of the 2011 Christchurch earthquake, the $\Delta \sigma_{f}$ are $0.013,0.044,0.033$, and $0.053 \mathrm{MPa}$ for the four different slip models, respectively-all above 0.01 $\mathrm{MPa}$, the presumed threshold value for earthquake triggering. 

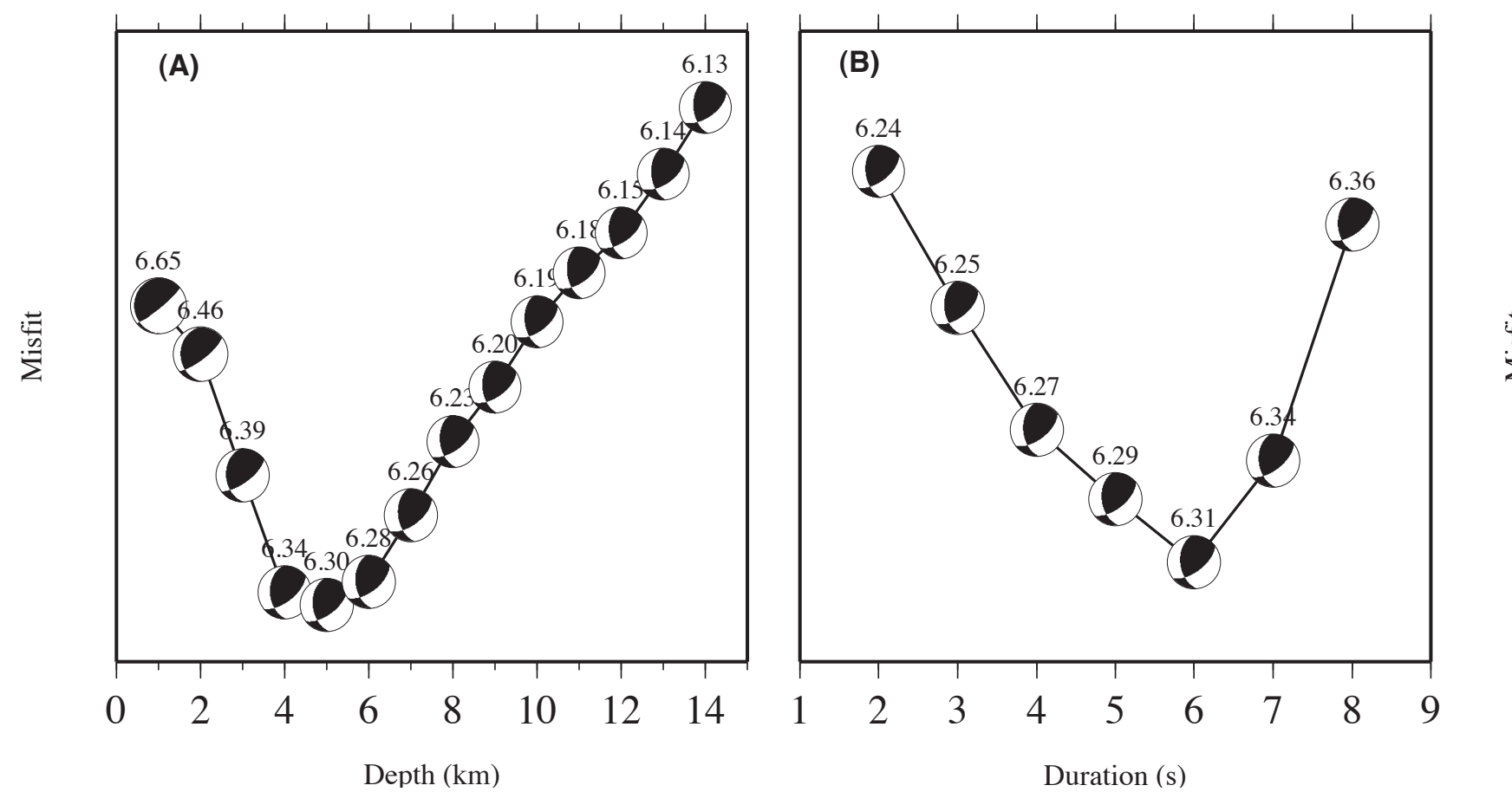

A Figure 8. Misfit of teleseismic waveforms as a function of earthquake focal depth and duration. The best fitting focal mechanisms and magnitudes are also plotted to show the trade-offs between them.

\begin{tabular}{|lcccc|}
\hline \multicolumn{5}{|c|}{ TABLE 1 } \\
Multilayered lithosphere model from CRUST 2.0. \\
\hline Layer & $\begin{array}{c}\text { Thickness } \\
(\mathbf{k m})\end{array}$ & $\begin{array}{c}\mathbf{V}_{\mathbf{p}} \\
\left(\mathbf{k m} \cdot \mathbf{s}^{-\mathbf{1}}\right)\end{array}$ & $\begin{array}{c}\text { Vs } \\
\left(\mathbf{k m} \cdot \mathbf{s}^{-\mathbf{1}}\right)\end{array}$ & $\begin{array}{c}\text { Density } \\
\left(\mathbf{k g} \cdot \mathbf{m}^{-\mathbf{3}}\right)\end{array}$ \\
\hline Upper crust & 14.3 & 6.0 & 3.5 & 2700 \\
Middle crust & 9 & 6.6 & 3.7 & 2900 \\
Lower crust & 11 & 7.2 & 4.0 & 3050 \\
Mantle & & 8.0 & 4.6 & 3300 \\
\hline
\end{tabular}

\section{Effect of Focal Depth on Coulomb Stress Change}

The sensitivity of our results to focal depth of the 2011 Christchurch earthquake is explored by comparing the $\Delta \sigma_{f}$ distributions resolved at depths of 2, 5, 10, and $15 \mathrm{~km}$. Here the focal depth is meant to be hypocentral depth, where rupture of the Christchurch earthquake initiated. The depth inferred from waveform inversion is essentially centroid depth, and the hypocentral depth is typically difficult to resolve unless with a dense local seismic network. For these calculations, we use the two-segment slip model of the mainshock along with the focal mechanism of the receiving fault $\left(52^{\circ} / 61^{\circ} / 128^{\circ}\right)$ derived from the teleCAP inversion. The results are shown in Figure 10. Some local changes of the $\Delta \sigma_{f}$ distribution are observed in the far field, and complex changes happen in the near field. For example, the area with positive $\Delta \sigma_{f}$ at the east end of the Greendale fault is getting smaller when focal depth increases; and in the area of the mainshock thrust fault segment, $\Delta \sigma_{f}$ changes polarity as the depth increases. The $\Delta \sigma_{f}$ at the 2011 Christchurch earthquake epicenter are $0.035,0.044,0.065$, and $0.094 \mathrm{MPa}$ at 2, 5, 10, and $15 \mathrm{~km}$ depth, respectively, increas- ing with the depth and all above $0.01 \mathrm{MPa}$. Similar results are obtained for the other slip models, as shown in Table 2.

\section{Effect of Receiving Fault Geometry on Coulomb Stress Change}

To analyze the impact of receiving fault geometry on the $\Delta \sigma_{f}$ we make some significant changes in the strike and dip of the receiver fault (from focal mechanism) and compare their influence on the resulting $\Delta \sigma_{f}$ distributions. The two-segment slip model of the mainshock and a focal depth of $5 \mathrm{~km}$ are adopted in this calculation, and the results are shown in Figures 11 (strike sensitivity) and 12 (dip sensitivity). In Figure 11, significant changes in the $\Delta \sigma_{f}$ distribution can be observed as the strike varies. When the strike of the receiving fault is rotated counterclockwise by 30 degrees, the area with positive $\Delta \sigma_{f}$ increases in the near- and far-fields, compared with Figure 10. The opposite situation occurs when the strike of the receiving fault is rotated clockwise from the teleCAP solution. Similar changes are also obtained when the dip angle of the receiving fault is changed by \pm 20 degrees, as shown in Figure 12 . The area with positive $\Delta \sigma_{f}$ outside the northwest corner of the Greendale fault grows with increasing dip angle. In the near-field, the situation is a little more complex, but the whole region with positive $\Delta \sigma_{f}$ gets larger. From these two figures, we conclude that the $\Delta \sigma_{f}$ distribution can be quite sensitive to the assumed geometry of the receiving fault.

\section{Sensitivity of Coulomb Stress Change to Coefficient of Friction}

The selection of an appropriate value for the apparent coefficient of friction $\mu^{\prime}$ is important because it controls the con- 

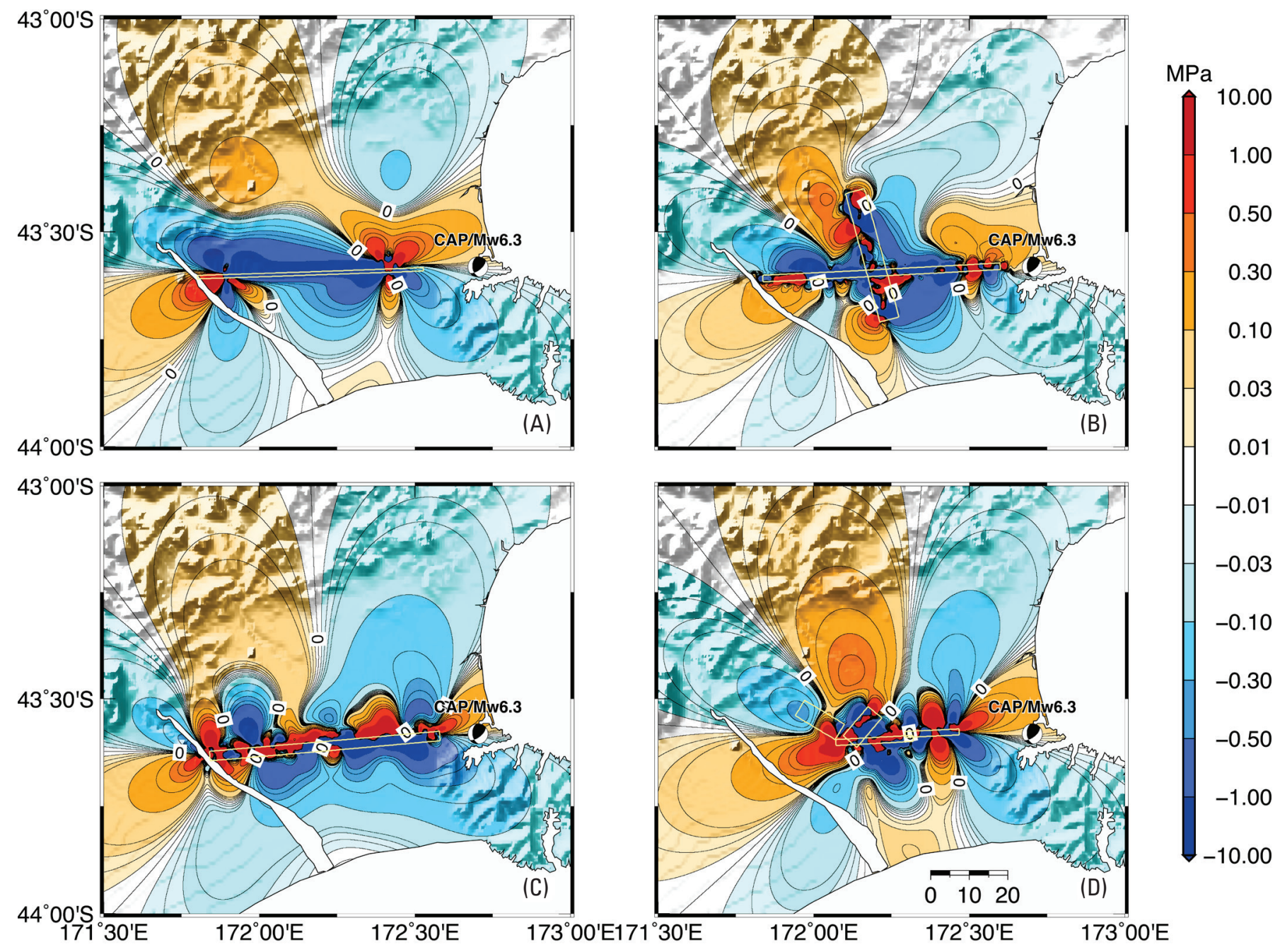

$\Delta$ Figure 9. The coseismic $\Delta \sigma_{f}$ caused by the $M_{w} 7.0$ earthquake with different slip models: A) a single fault plane model with uniform slip; B) a two-segment slip model; C) a stochastic model with single plane based on the National Earthquake Information Center (NEIC) solution; D) a stochastic model with four segments based on Beavan et al. (2010). The strike angle, dip angle, and rake angle of the receiver fault are $52^{\circ}, 61^{\circ}$, and $128^{\circ}$, respectively. The calculated depth is $5 \mathrm{~km}$, and the apparent coefficient of friction $\mu^{\prime}$ is 0.4 . The two focal mechanisms show the location and mechanism of the mainshock and $M_{w} 6.3$ aftershock.

tribution of the normal stress change to the $\Delta \sigma_{f}$ (Xiong et al. 2000; King et al. 1994). In general, $\mu^{\prime}$ is set to be different values for different types of faults. Xiong et al. (2010) set $\mu^{\prime}$ to a high value $(0.8)$ for thrust faults, a moderate value $(\sim 0.6)$ for normal faults, and a lower value $(0.2 \sim 0.4)$ for strike-slip faults. Since the 2010 Canterbury earthquake mainshock is primarily a strike-slip event (with some thrust component), we have set $\mu^{\prime}$ at 0.4 in the previous calculations. Here we consider values of $\mu^{\prime}$ of 0.0 and 0.8 to analyze their sensitivity on the computed $\Delta \sigma_{f}$ distribution. In these calculations, we again use the two-segment slip model for the mainshock along with the teleCAP mechanism $\left(52^{\circ} / 61^{\circ} / 128^{\circ}\right)$ and focal depth $(5 \mathrm{~km})$ for the aftershock. The resulting $\Delta \sigma_{f}$ at the epicenter of the 2011 Christchurch earthquake is $0.095,0.044$, and -0.008 $\mathrm{MPa}$ for $\mu^{\prime}=0.0,0.4$, and 0.8 , respectively, as shown in Figure 13. The decrease of $\Delta \sigma_{f}$ with increasing $\mu^{\prime}$ indicates that the change of normal stress is positive (clamping the fault plane)
Christchurch fault plane. Other areas, such as northwest of the Greendale fault, exhibit an increase in $\Delta \sigma_{f}$ with increasing $\mu^{\prime}$. Obviously, the polarity change of $\Delta \sigma_{f}$ can lead to significant uncertainty for evaluating seismic hazard, underscoring the need for accurate constraints on mainshock faulting mechanism and estimation of $\mu^{\prime}$.

\section{DISCUSSION AND CONCLUSION}

Coulomb stress triggering is physically straightforward and has been widely applied in studying the distribution and probability of aftershocks. However, there can be substantial variability due to uncertainty in mainshock slip models and fault orientation of the subsequent aftershocks. In this paper, we calculate the coseismic static Coulomb stress change caused by the 2010 Canterbury earthquake for several different mainshock slip models, and various permutations of receiving fault geometry 

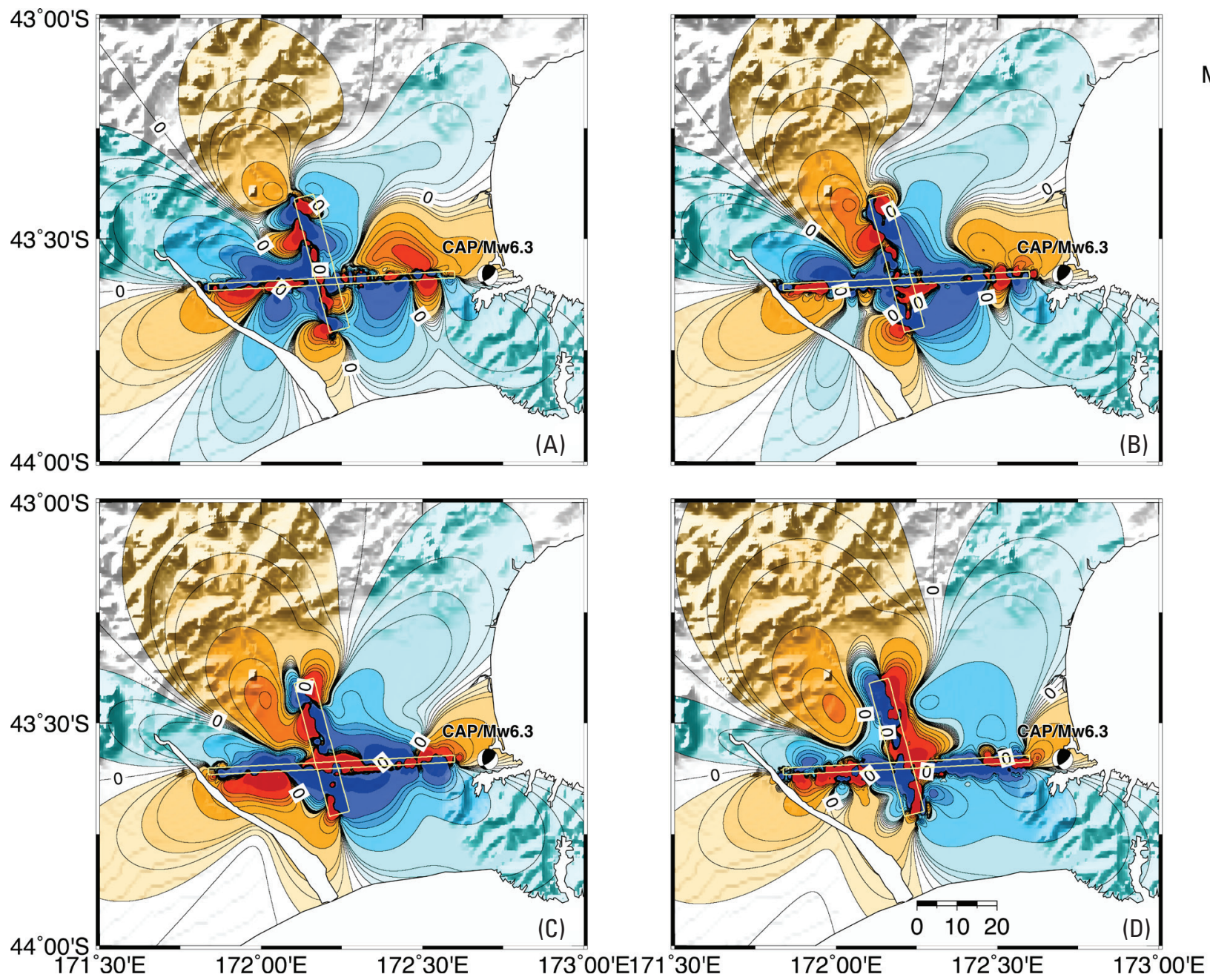

0.50

0.30

0.10

0.03

0.01

$-0.01$

$-0.03$

$-0.10$

$-0.30$

$-0.50$

$-1.00$

$\Delta$ Figure 10. The coseismic $\Delta \sigma_{f}$ caused by the mainshock with the two-segment slip model at different depths, with $\mu^{\prime}=0.4$. A), B), C), and D) show results for depths of $2 \mathrm{~km}, 5 \mathrm{~km}, 10 \mathrm{~km}$, and $15 \mathrm{~km}$, respectively. The strike angle, dip angle, and rake angle of receiver fault are $52^{\circ}, 61^{\circ}$, and $128^{\circ}$, respectively. The beach balls show the location and mechanism of the mainshock and $M_{w} 6.3$ aftershock.

TABLE 2

$\Delta \sigma_{f}$ at the 2011 Christchurch earthquake epicenter, caused by different mainshock models with three $\mu^{\prime}$ values at four focal depths. The focal mechanism of the receiving fault is $52^{\circ} / 61^{\circ} / 128^{\circ}$.

\begin{tabular}{|c|c|c|c|c|c|}
\hline & \multirow[b]{2}{*}{$\mu^{\prime}$} & \multicolumn{4}{|c|}{ Depth } \\
\hline & & $2 \mathrm{~km}$ & $5 \mathrm{~km}$ & 10 km & $15 \mathrm{~km}$ \\
\hline \multirow[t]{3}{*}{ Uniform fault plane model } & 0.0 & 0.062 & 0.062 & 0.066 & 0.081 \\
\hline & 0.4 & 0.010 & 0.013 & 0.021 & 0.036 \\
\hline & 0.8 & -0.042 & -0.036 & -0.023 & -0.008 \\
\hline \multirow[t]{3}{*}{ Two-segment slip model } & 0.0 & 0.087 & 0.095 & 0.113 & 0.143 \\
\hline & 0.4 & 0.035 & 0.044 & 0.065 & 0.094 \\
\hline & 0.8 & -0.018 & -0.008 & 0.017 & 0.044 \\
\hline \multirow{3}{*}{$\begin{array}{l}\text { Stochastic model with single } \\
\text { plane based on NEIC solution }\end{array}$} & 0.0 & 0.110 & 0.143 & 0.183 & 0.214 \\
\hline & 0.4 & 0.004 & 0.033 & 0.086 & 0.131 \\
\hline & 0.8 & -0.103 & -0.077 & -0.010 & 0.048 \\
\hline \multirow{3}{*}{$\begin{array}{l}\text { Stochastic model with four } \\
\text { segments }\end{array}$} & 0.0 & 0.120 & 0.119 & 0.114 & 0.121 \\
\hline & 0.4 & 0.048 & 0.053 & 0.058 & 0.068 \\
\hline & 0.8 & -0.023 & -0.013 & 0.002 & 0.015 \\
\hline
\end{tabular}



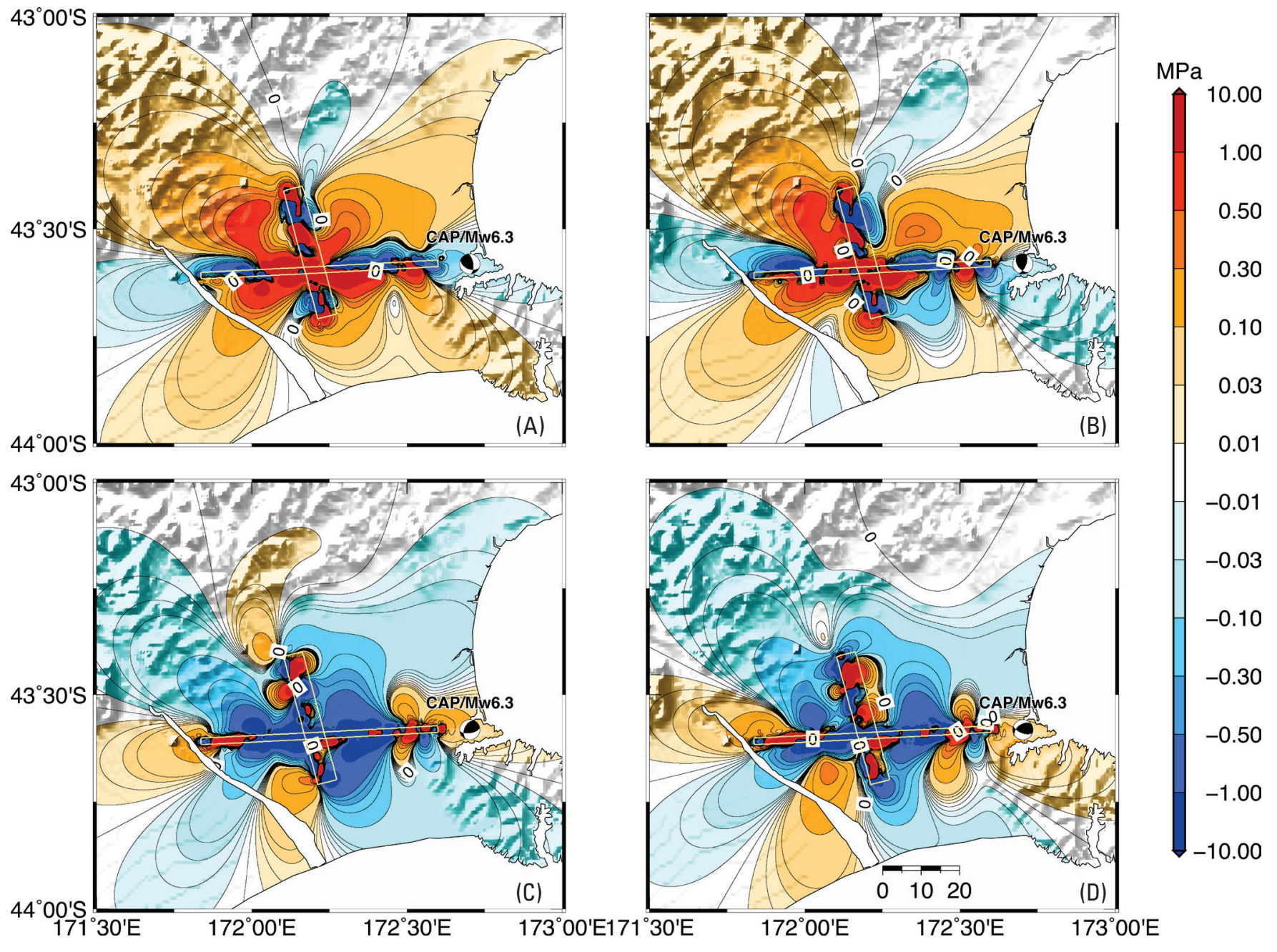

$\Delta$ Figure 11. The coseismic $\Delta \sigma_{f}$ caused by the two-segment slip model at a focal depth of $5 \mathrm{~km}$ with $\mu^{\prime}=0.4$ for variations in receiver fault strike. A), B), C), and D) show results for strikes of $352^{\circ}, 22^{\circ}, 82^{\circ}$, and $112^{\circ}$, respectively. The dip and rake of the receiver fault are held constant at $61^{\circ}$ and $128^{\circ}$, respectively, in these calculations. The beach balls show the location and mechanism of the mainshock and $M_{w} 6.3$ aftershock.

at different focal depths with three values of apparent coefficient of friction. We find that different slip models can result in significant differences in the amplitude and distribution of $\Delta \sigma_{f}$ in the near field of the fault, but no substantial difference in the far field. On the other hand, focal depth and receiving fault geometry play a much stronger role on $\Delta \sigma_{f}$ outside the immediate mainshock rupture zone. In our calculations for the 2011 Christchurch earthquake, $\Delta \sigma_{f}$ can increase significantly (by a factor of 3) when the aftershock focal depth increases from $2 \mathrm{~km}$ to $15 \mathrm{~km}$. Additionally, our results show a change of 30 degrees in receiving fault geometry can even cause polarity changes in $\Delta \sigma_{f}$. We also find the resulting $\Delta \sigma_{f}$ at the epicenter of the 2011 Christchurch earthquake decreases significantly as the value of apparent coefficient of friction $\left(\mu^{\prime}\right)$ increases. This emphasizes the need for careful consideration of the appropriate value of $\mu^{\prime}$ for different faulting environments. It should be noted that in this study we assume that the coseismic slip distribution of the Canterbury mainshock is responsible for the triggering of the Christchurch earthquake. Because the GPS measurements after the Canterbury earthquake show very little postseismic motion (less than $\sim 2 \%$ of coseismic) (Reyners 2011, this issue), postseismic deformation probably can be neglected. However we still cannot rule out the possibility that smaller aftershocks triggered the Christchurch earthquake as a secondary aftershock with larger magnitude (e.g., Felzer et al. 2002).

In general, we find the occurrence of the Canterbury earthquake with a reasonable set of parameter choices raises the $\Delta \sigma_{f}$ on the Christchurch fault plane beyond the 0.01 MPa threshold, promoting the aftershock plane to break. To improve the accuracy of $\Delta \sigma_{f}$ analysis, and hence the probability assessment of aftershocks, it is helpful to carefully study source parameters of historical earthquakes for each region to understand the potential receiving fault geometry. For $\mathbf{M}>5.5$ earthquakes, the teleCAP technique used in this paper shows promise for obtaining accurate focal mechanism and depth. For $\mathbf{M} \sim 5$ earthquakes not recorded with local broadband seismic stations, teleseismic $P$ waves are typically above noise level in the short-period band $(\sim 1 \mathrm{~Hz})$, and teleCAP can be 

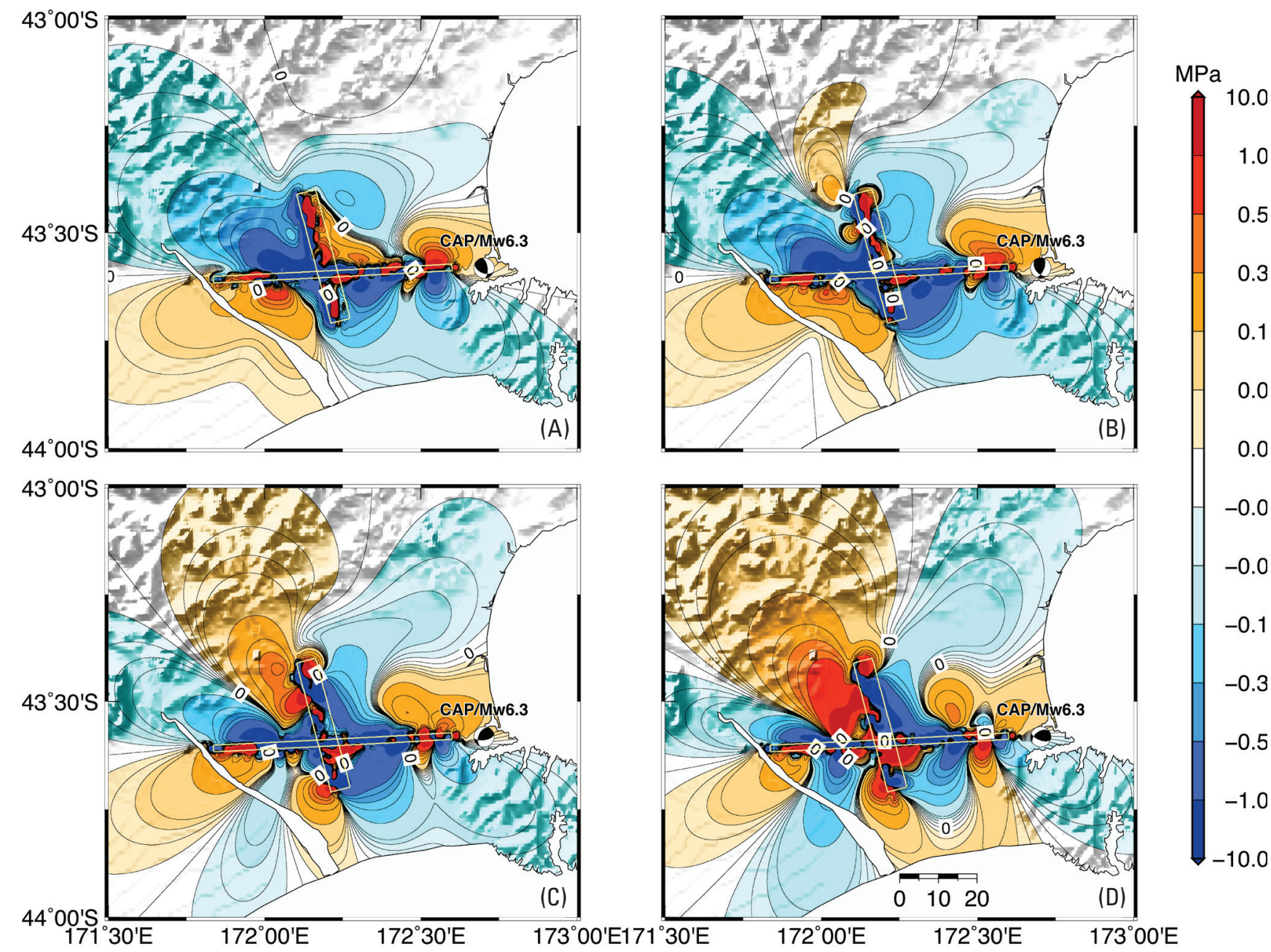

A Figure 12. The coseismic $\Delta \sigma_{f}$ caused by the two-segment slip model at a focal depth of $5 \mathrm{~km}$ with $\mu^{\prime}=0.4$ for variations in receiver fault dip. A), B), C), and D) show results for dips of $21^{\circ}, 41^{\circ}, 61^{\circ}$, and $81^{\circ}$, respectively. The strike and rake of the receiver fault are held constant at $52^{\circ}$ and $128^{\circ}$, respectively, in these calculations. The beach balls show the location and mechanism of the mainshock and $M_{w} 6.3$ aftershock.

also applied, although the variability of $P$-wave amplitude has to be taken into account (Ni et al. 2010; Chu et al. 2011). For $\mathbf{M} \sim 5$ earthquakes well recorded with local stations, the traditional CAP technique can be applied to estimate source parameters. For even smaller earthquakes (M 2-4), Tan and Helmberger (2007) have proposed a new amplitude correction technique to invert short-period $(0.5-2 \mathrm{~Hz}) P$ waveforms for source parameters, and achieved success in the 2003 Big Bear sequence. Since focal mechanism itself cannot distinguish between the fault plane and auxiliary fault plane, additional information is needed, for example from aftershock distribution or earthquake rupture directivity (e.g., Luo et al. 2010). Paleoseismology and geology can also provide important information on potential fault orientations, particularly for regions without active seismicity. $\ll$

\section{ACKNOWLEDGMENTS}

Constructive reviews provided by Jeanne Hardebeck, Morgan Page, and an anonymous reviewer were very helpful in revis- ing the paper and making it acceptable for publication. This work is supported by China Earthquake Administration fund 200808078, and NSFC fund 40821160549, 41074032.

\section{REFERENCES}

Allen, R. M., and H. Kanamori (2003). The potential of earthquake early warning in southern California. Science 300 (5,620), 786-789.

Bakun, W. H., F. G. Fischer, E.g. Jensen, and J. VanSchaack (1994). Early warning system for aftershocks. Bulletin of the Seismological Society of America 84 (2), 359-365.

Bassin, C., G. Laske, and G. Masters (2000). The current limits of resolution for surface wave tomography in North America. Eos, Transactions, American Geophysical Union 81, F897.

Beavan, J., S. Samsonov, M. Motagh, L. Wallace, S. Ellis, and N. Palmer (2010). The Darfield (Canterbury) earthquake: Geodetic observations and preliminary source model. Bulletin of the New Zealand Society for Earthquake Engineering 43 (4), 228-235.

Chu, R., S. Ni, A. Pitarka, and D. V. Helmberger (2011). Inversion of source parameters for moderate earthquakes using short-period teleseismic $P$ waves. Submitted to Geophysical Journal International. 

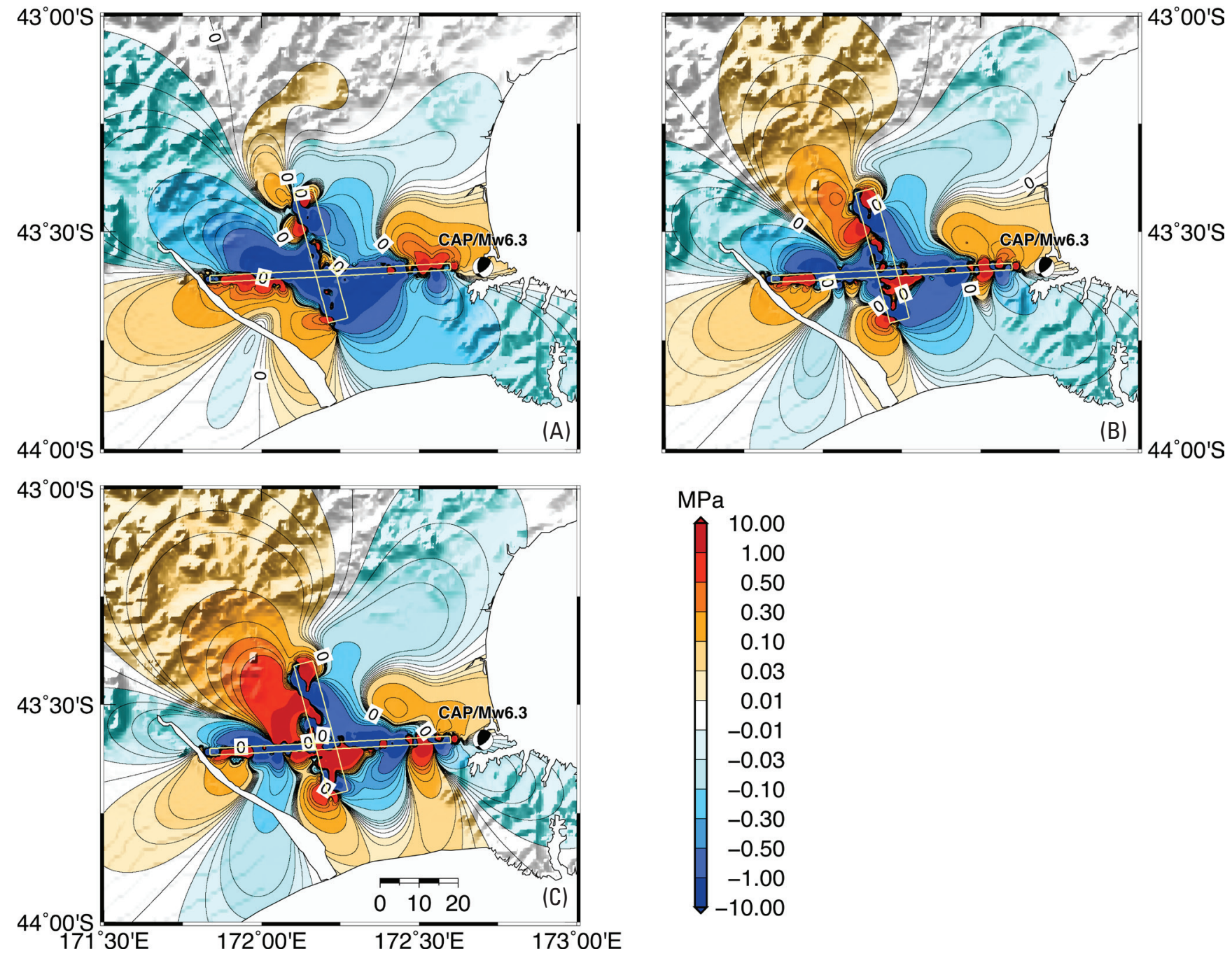

$\Delta$ Figure 13. The coseismic $\Delta \sigma_{f}$ caused by the two-segment slip model for different values of apparent coefficient of friction $\mu^{\prime}$ at a depth of $5 \mathrm{~km}$ with a receiver fault mechanism of $52^{\circ} / 61 \% 128^{\circ}$. A), B), and C) show results for $\mu^{\prime}$ of $0.0,0.4$, and 0.8 , respectively.

Dahlen, F. A., and J. Tromp (1998). Theoretical Global Seismology. Princeton, NJ: Princeton University Press.

Dreger, D. S., and D. V. Helmberger (1993), Determination of Source Parameters at Regional Distances with Single Station or Sparse Network Data, Journal of Geophysical Research 98, 8,107-8,125.

Felzer, K. R., T. W. Becker, R. E. Abercrombie, G. Ekström, and J. R. Rice (2002), Triggering of the 1999 MW 7.1 Hector Mine earthquake by aftershocks of the 1992 MW 7.3 Landers earthquake, Journal of Geophysical Research 107 B92190; doi:10.1029/2001JB000911.

Felzer, K. R., and E. E. Brodsky (2006). Decay of aftershock density with distance indicates triggering by dynamic stress. Nature $\mathbf{4 4 1}$, $735-738$.

Freed, A. M. (2004). Earthquake triggering by static, dynamic, and postseismic stress transfer. Annual Review of Earth and Planetary Sciences 33, 335-367.

Freed, A. M., and J. Lin (2001). Delayed triggering of the 1999 Hector Mine earthquake by viscoelastic stress transfer. Nature 411, 180183.

Graves, R., and A. Pitarka (2010). Broadband ground motion simulation using a hybrid approach. Bulletin of the Seismological Society of America 100, 2,095-2,123; doi: 10.1785/0120100057.

Harris, R. A. (1998). Introduction to special section: Stress triggers, stress shadows, and implications for seismic hazard. Journal of Geophysical Research 103, 24,347-24,358.
Harris, R. A. (2000). Earthquake stress triggers, stress shadows, and seismic hazard. Current Science 79 (9), 10.

Jaeger, J. C., N. G. W. Cook, and R. W. Zimmerman (2007). Fundamentals of Rock Mechanics, fourth edition. Wiley-Blackwell.

Ji, C., D. J. Wald, and D. V. Helmberger (2002a). Source description of the 1999 Hector Mine, California, earthquake, part I: Wavelet domain inversion theory and resolution analysis. Bulletin of the Seismological Society of America 92 (4), 1,192-1,207.

Ji, C., D. J. Wald, and D. V. Helmberger (2002b). Source description of the 1999 Hector Mine, California, earthquake, part II: Complexity of slip history. Bulletin of the Seismological Society of America 92 (4), $1,208-1,226$

King, G. C. P., R. S. Stein, and J. Lin (1994). Static stress changes and the triggering of earthquakes. Bulletin of the Seismological Society of America 84, 935-953.

Lavallée, D., and R. J. Archuleta (2003). Stochastic modeling of slip spatial complexities for the 1979 Imperial Valley, California, earthquake. Geophysical Research Letters 30 (5), 1,245; doi:10.1029/2002GL015839.

Liu, P., R. J. Archuleta, and S. H. Hartzell (2006). Prediction of broadband ground-motion time histories: Hybrid low/high frequency method with correlated random source parameters. Bulletin of the Seismological Society of America 96, 2,118-2,130. 
Luo, Y., Y. Tan, S. Wei, D. Helmberger, Z. Zhan, S. Ni, E. Hauksson, and Y. Chen (2010). Source mechanisms and rupture directivity of the May 18, 2009 Mw 4.6 Inglewood, California earthquake. Bulletin of the Seismological Society of America 100 (6), 3,269-3,277.

Ma, K.-F., C.-H. Chan, and R. S. Stein (2005). Response of seismicity to Coulomb stress triggers and shadows of the $1999 \mathrm{Mw}=7.6$ Chi-Chi, Taiwan, earthquake. Journal of Geophysical Research 110, B05S19.

Mai, P. M., and G. C. Beroza (2002). A spatial random field model to characterize complexity in earthquake slip. Journal of Geophysical Research 107 (B11); doi:10.1029/2001JB000588.

Nalbant, S. S., A. Hubert, and G. C. P. King (1998). Stress coupling between earthquakes in northwest Turkey and the north Aegean Sea. Journal of Geophysical Research 103, 24,469-24,486.

Ni, S., A. Pitarka, and D. V. Helmberger (2010). Rapid source estimation from global calibrated paths. Seismological Research Letters 81 (3), 498-504; doi: 10.1785/gssrl.82.6.498.

Okada, Y. (1992). Internal deformation due to shear and tensile faults in a half-space. Bulletin of the Seismological Society of America $\mathbf{8 2}$, $1,018-1,040$.

Parsons, T., R. S. Stein, R. W. Simpson, and P. A. Reasenberg (1999). Stress sensitivity of fault seismicity: A comparison between limitedoffset oblique and major strike slip faults. Journal of Geophysical Research 104, 20,183-20,202.

Parsons, T., S. Toda, R. S. Stein, A. Barka, and J. H. Dieterich (2000). Heightened odds of large earthquakes near Istanbul: An interaction-based probability calculation. Science $\mathbf{2 8 8}, 661$.

Quigley, M., P. Villamor, K. Furlong, J. Beavan, R. Van Dissen, N. Litchfield, T. Stahl, B. Duffy, E. Bilderback, D. Noble, D. Barrell, R. Jongens, and S. Cox (2010). Previously unknown fault shakes New Zealand's South Island. Eos, Transactions, American Geophysical Union 91, 469-472; doi:10.1029/2010EO490001.

Reilinger, R. E., S. Ergintav, R. Bürgmann, S. McClusky, O. Lenk, A. Barka, O. Gurkan et al. (2000). Coseismic and postseismic fault slip for the 17 August 1999, $\mathbf{M}=7.5$, Izmit, Turkey earthquake. Science 289, 1,519-1,524.

Reyners, M. (2011). Lessons from the destructive $M w 6.3$ Christchurch, New Zealand, earthquake. Seismological Research Letters 82(3), 371-372.

Scholz, C. H. (1990). The Mechanics of Earthquakes and Faulting. New York: Cambridge University Press, 439 pp.

Shan, B., X. Xiong, Y. Zheng, and F. Diao (2009). Stress changes on major faults caused by $M w 7.9$ Wenchuan earthquake, May 12, 2008. Science in China, Series D-Earth Sciences 52 (5), 593-601; doi:10.1007/s11430-009-0060-9.

Stein, R. S. (1999). The role of stress transfer in earthquake occurrence. Nature $\mathbf{4 0 2}$ (6,762), 605-609.

Stein, R. S., A. A. Barka, and J. H. Dieterich (1997). Progressive failure on the North Anatolian fault since 1939 by earthquake stress triggering. Geophysical Journal International 128, 594-604.

Stein, R. S., G. C. P. King, and J. Lin (1994). Stress triggering of the 1994 $\mathrm{M}=6.7$ Northridge, California, earthquake by its predecessors, Science 265, 1,432-1,435.

Talebian, M., J. Biggs, M. Bolourchi, A. Copley, A. Ghassemi, M. Ghorashi, J. Hollingsworth, J. Jackson, E. Nissen, B. Oveisi, B. Parsons, K. Priestley, and A. Saiidi (2006). The Dahuiyeh (Zarand) earthquake of 2005 February 22 in central Iran: Reactivation of an intramountain reverse fault. Geophysical Journal International 164 (1), 137-148.
Tan, Y., L. Zhu, D. V. Helmberger, and C. K. Saikia (2006). Locating and modeling regional earthquakes with two stations. Journal of Geophysical Research 111, B01306; doi:10.1029/2005JB003775.

Tan, Ying, and Don Helmberger (2007). A New Method for Determining Small Earthquake Source Parameters Using Short-Period P Waves. Bulletin of the Seismological Society of America 97 (4): 1,176-1,195; doi: $10.1785 / 0120060251$.

Toda, S., J. Lin, M. Meghraoui, and R. S. Stein (2008). 12 May 2008 $\mathbf{M}=7.9$ Wenchuan, China, earthquake calculated to increase failure stress and seismicity rate on three major fault systems. Geophysical Research Letters 35, L17305.

Toda, S., R. Stein, P. Reasenberg, J. Dieterich, and A. Yoshida (1998). Stress transferred by the $M w=6.5$ Kobe, Japan, shock: Effect on aftershocks and future earthquake probabilities. Journal of Geophysical Research 103, 24,543-24,565.

Van Dissen, R., D. Barrell, N. Litchfield, P. Villamor, M. Quigley, A. King, K. Furlong, et al. (2011). Surface rupture displacement on the Greendale fault during the $M w 7.1$ Darfield (Canterbury) earthquake, New Zealand, and its impact on man-made structures. Proceedings of the Ninth Pacific Conference on Earthquake Engineering, 14-16 April 2011, 186-193.

Wallace, L. M., and J. Beavan (2006). A large slow slip event on the central Hikurangi subduction interface beneath the Manawatu region, North Island, New Zealand. Geophysical Research Letters 33, L11301; doi:10.1029/2006GL026009.

Wan, K., S. Ni, X. Zeng, and S. Paul (2009). Real-time seismology for the 05/12/2008 Wenchuan earthquake of China: A retrospective view. Science in China, Series D-Earth Sciences 52 (2), 155-165.

Wang, R., F. Lorenzo Martín, and F. Roth (2003). Computation of deformation induced by earthquakes in a multi-layered elastic crust-FORTRAN programs EDGRN/EDCMP. Computers \& Geoscience 29 (2), 195-207.

Wang, R., F. Lorenzo-Martín, and F. Roth (2006). PSGRN/PSCMP_a new code for calculating co- and post-seismic deformation, geoid and gravity changes based on the viscoelastic-gravitational dislocation theory. Computers \& Geoscience 32, 527-541.

Wang, W., S. Ni, Y. Chen, and H. Kanamori (2009). Magnitude estimation for early warning applications using the initial part of $P$ waves: A case study on the 2008 Wenchuan sequence. Geophysical Research Letters 36, L16305; doi:10.1029/2009GL038678.

Xiong, X, B. Shan, Y. Zheng, and R. Wang (2010). Stress transfer and its implication for earthquake hazard on the Kunlun fault, Tibet. Tectonophysics $\mathbf{4 8 2}, 216-225$.

Zhao, L. S., and D. V. Helmberger (1994). Source estimation from broadband regional seismograms. Bulletin of the Seismological Society of America 84, 91-104.

Zhang, G., L. Zhu, X. Song, Z. Li, M. Yang, N. Su, and X. Chen (1999). Predictions of the 1997 strong earthquakes in Jiashi, Xinjiang, China. Bulletin of the Seismological Society of America 89 (5), $1,171-1,183$.

Zhu, L., and D. V. Helmberger (1996). Advancements in source estimation techniques using broadband regional seismograms. Bulletin of the Seismological Society of America 86, 1,634-1,641.

Seismological Laboratory California Institute of Technology Pasadena, California 91125, U.S.A. zwzhan@gmail.com (Z.Z.) 